\title{
Serum Antioxidant Parameters are Significantly Increased in Patients with Type 2 Diabetes Mellitus after Consumption of Chinese Propolis: A Randomized Controlled Trial Based on Fasting Serum Glucose Level
}

\author{
Weina Gao (D) Lingling Pu - Jingyu Wei - Zhanxin Yao • \\ Yawen Wang · Tala Shi · Liting Zhao • Changya Jiao • \\ Changjiang Guo
}

Received: July 23, 2017 / Published online: December 6, 2017

(C) The Author(s) 2017. This article is an open access publication

\section{ABSTRACT}

Introduction: Propolis is a natural product with many biological activities. The present study was designed to evaluate the effects of Chinese propolis on glucose metabolism, antioxidant function, and inflammatory cytokines in patients with type 2 diabetes mellitus (T2DM).

Methods: In the 18-week study, recruited T2DM patients were randomly divided into a Chinese propolis group ( $900 \mathrm{mg} /$ day) $(n=31)$ and a control group $(n=30)$ according to fasting serum glucose levels at baseline.

Results: At the end of the study, no significant difference was found between the groups in serum glucose, glycosylated hemoglobin, insulin, aldose reductase, or adiponectin. However, serum GSH, flavonoids, and polyphenols were

Enhanced content To view enhanced content for this article go to http://www.medengine.com/Redeem/ E9ECF060647F55E0.

W. Gao $\cdot$ L. Pu $(\bowtie) \cdot$ J. Wei $\cdot$ Z. Yao $\cdot$ Y. Wang ·

T. Shi · L. Zhao · C. Guo $(\varangle)$

Department of Nutrition, Tianjin Institute of Health

and Environmental Medicine, Tianjin, People's

Republic of China

e-mail: Pulingling@163.com

C. Guo

e-mail: guocjtj@126.com

C. Jiao

Nutrition and Health Research Center, By-Health

Ltd, Guangzhou, People's Republic of China significantly increased, and serum lactate dehydrogenase activity was significantly reduced in the Chinese propolis group. Meanwhile, serum IL-6 was significantly increased in the Chinese propolis group.

Conclusion: Chinese propolis is effective at improving antioxidant function in T2DM patients, partly by increasing serum antioxidant parameters.

Keywords: Antioxidant function; Chinese propolis; Type 2 diabetes mellitus

\section{INTRODUCTION}

Propolis is a resinous hive material produced by bees from exudates and buds of numerous plants in combination with secreted substances from bee metabolism, pollen, and beewaxes. Propolis is rich in active components such as polyphenols (including flavonoids), terpenoids, sugars, hydrocarbons, minerals, vitamins, amino acids, and other bioactive constituents [1-3]. Propolis has been used for many years in folk medicine because it possesses various biological properties, including antioxidant, antimicrobial, antiparasite, anticancer, and antiinflammatory activities [4-8].

Previously, propolis was demonstrated to improve glucose metabolism and insulin sensitivity, decrease the plasma insulin resistance index, ameliorate oxidative stress, and prevent 
or delay the occurrence of diabetic complications in diabetic rats $[2,9,10]$. We showed that both Chinese and Brazilian green propolis decreased the serum glucose level and improved antioxidant function in rats with DM [11]. In a clinical trial, we found that Brazilian green propolis improved antioxidant function and modulated inflammatory cytokines in T2DM patients after an 18-week intervention. Based on a chemical analysis, Brazilian green and Chinese propolis were found to differ significantly in antioxidant component composition. The contents of flavonoids, zinc, and selenium were lower in Brazilian green propolis than in Chinese propolis, whereas the polyphenol content was higher [12]. We hypothesize that propolis from different geographical areas may act differently because they differ in chemical composition. Therefore, the study reported in the present paper aimed to investigate the effects of Chinese propolis on glucose metabolism, antioxidant function, and inflammatory cytokines in patients with T2DM.

\section{METHODS}

\section{Study Subjects}

From May to September 2013, 61 T2DM patients aged 35-78 years were recruited from the Department of Endocrinology, Pingjin Hospital, Tianjin, China. T2DM was diagnosed in accordance with the criteria of the American Diabetes Mellitus Association [13]. Patients with allergies, those using other functional foods or health products containing antioxidants, those taking medications (including hormonal contraceptives), substance abusers (e.g., alcohol intake $>60 \mathrm{~g} /$ day for men and $>40 \mathrm{~g} /$ day for women) [14], smokers (smoking index $\geq 400$ ) [15], and those with serious endocrine, cardiovascular, renal, respiratory, gastrointestinal, hematological, or central nervous system diseases, acute inflammation or infection, active cancers, or psychiatric disorders were excluded from the study. Serious conditions or diseases were checked and confirmed by senior doctors based on international or national criteria. For example, T2DM patients with severe heart failure, chronic kidney disease, or severe Parkinsonism were excluded [16-18]. Pregnant or lactating women were also excluded.

The protocol was approved by the ethics committee of the Tianjin Institute of Health and Environmental Medicine (TIHE-TY20130428). All procedures followed were in accordance with the ethical standards of the responsible committee on human experimentation (institutional and national) and with the Helsinki Declaration of 1964, as revised in 2013. Informed consent was obtained from all patients before they were included in the study. This trial was not registered because we signed a contract with By-Health Ltd. in which registration was not required.

\section{Study Design}

The design of the present study was not randomized completely. At baseline, we divided the enrolled patients into Chinese propolis and control groups based on fasting serum glucose levels (the fasting blood glucose criterion used in the current study was $\geq 7.0 \mathrm{mmol} / \mathrm{L}$ ). Briefly, fasting serum glucose values were ranked from the lowest to the highest. The two patients with consecutive glucose values were grouped by lot. It was an open-label study. Subjects in the Chinese propolis group took Chinese propolis capsules provided by Feng-Language Co., Ltd. (Hangzhou, China) at a dose of $900 \mathrm{mg}$ daily for 18 weeks. The dose was extrapolated from animal experiments reported previously $[11,19]$.

Body height, weight, and waist and hip circumferences were measured at baseline. Body mass index (BMI) was calculated as body weight $(\mathrm{kg}) /(\text { body height }(\mathrm{m}))^{2}$, and waist-to-hip ratio (WHR) as waist $(\mathrm{cm}) /$ hip $(\mathrm{cm})$. Fasting blood samples were collected at baseline, and the fasting period was $8 \mathrm{~h}$, from $23: 00 \mathrm{pm}$ to 7:00 am. Fasting blood samples from the antecubital vein were collected by vacuum tubes and sent to the clinical laboratory of Pingjin Hospital. Serum was separated by centrifugation within $4 \mathrm{~h}$. Parameters such as glucose, glycosylated hemoglobin, and insulin were assayed within $48 \mathrm{~h}$. Some of the blood samples were brought back to our laboratory at $<4{ }^{\circ} \mathrm{C}$. One 
milliliter of whole blood was taken to prepare samples for hemolysis. The remaining blood samples were centrifuged for serum collection and stored at $-20^{\circ} \mathrm{C}$ prior to the assessment of antioxidant parameters, activity of aldose reductase, adiponectin, and cytokines. Fasting blood samples were also collected at the end of the trial, and serum biochemical parameters were assayed again accordingly.

All treatments, exercise regimens, or diabetic diets were continued unchanged during the intervention period. Medications for type 2 diabetes, such as metformin, acarbose, glimepiride, repaglinide, and insulin, were consumed or injected daily as usual. In other words, the patients' usual medications were not altered during the intervention period. Some patients monitored their blood glucose at home; during the follow-up, those patients reported that their glucose levels were stable.

\section{Dietary Survey}

Experienced interviewers conducted a consecutive 5-day dietary survey using a 24 -h recall method. The energy and nutrient intakes were calculated based on the food intake and Chinese food composition data compiled by the Institute of Nutrition and Food Safety, Chinese Center for Disease Control and Prevention [20].

\section{Measurement of Blood Biochemical Parameters}

At the beginning and the end of the intervention, fasting blood samples from the antecubital vein were collected by vacuum tubes. Serum glucose and insulin were assayed using commercial kits purchased from BioSino Biotechnology and Science Inc. (Beijing, China) and Huanri Inc. (Shandong, China), respectively. Serum glycosylated hemoglobin was determined using a glycosylated hemoglobin analyzer (Bio-Rad Laboratories, Hercules, CA, USA). Serum aldose reductase, adiponectin, interleukin-1 $\beta$ (IL-1 $\beta$ ), interleukin-6 (IL-6), and tumor necrosis factor $\alpha$ (TNF- $\alpha)$ were measured using enzyme-linked immunosorbent assay
(ELISA) kits obtained from BD Biosciences (Lake Franklin, NJ, USA).

Serum antioxidant capacity was assayed via the ferric-reducing antioxidant power (FRAP) described by Benzie and Strain [21]. Serum malondialdehyde (MDA) was analyzed spectrophotometrically by reaction with thiobarbituric acid [22]. The activities of serum superoxide dismutase (SOD), glutathione peroxidase (GSH-Px), and lactate dehydrogenase $(\mathrm{LDH})$ as well as the content of reduced glutathione (GSH) and that of carbonyls were measured using commercial kits purchased from Jiancheng Bioengineering Institute (Nanjing, China). Total flavonoid content was measured with an aluminum chloride colorimetric assay [23]. Total polyphenol content in serum was determined spectrophotometrically using the Folin-Ciocalteu method [24].

\section{Statistical Analysis}

Statistical analysis was performed using the SPSS 10.0 software (SPSS Inc., Chicago, IL, USA). Data are expressed as the mean \pm standard deviation. Data were checked for normality by performing a Kolmogorov-Smirnov test before carrying out any further analysis. When the data distribution was normal, Student's $t$ test was used to analyze the difference between the two groups. The insulin, aldose reductase, and adiponectin data were transformed logarithmically because they were not normally distributed. $p<0.05$ was considered to indicate statistical significance.

\section{RESULTS}

\section{General Characteristics of the Patients at Baseline}

Sixty-one patients were initially recruited to participate in this study, and 55 of those patients completed the intervention. Six patients from the Chinese propolis group withdrew from the study because of allergies to Chinese propolis (four subjects) or for personal reasons (two subjects). No subjects in the control group withdrew from the experiment. As 
Table 1 General characteristics of the subjects at baseline

\begin{tabular}{|c|c|c|}
\hline Parameter & Control & $\begin{array}{l}\text { Chinese } \\
\text { propolis }\end{array}$ \\
\hline Subjects $(\mathrm{M} / \mathrm{F})$ & $30(14 / 16)$ & $31(11 / 20)$ \\
\hline Age (year) & $60.6 \pm 8.4$ & $57.7 \pm 7.5$ \\
\hline Body height $(\mathrm{cm})$ & $166.0 \pm 8.5$ & $164.6 \pm 8.0$ \\
\hline Body weight (kg) & $74.5 \pm 9.9$ & $70.0 \pm 10.4$ \\
\hline WHR & $0.9 \pm 0.1$ & $0.9 \pm 0.1$ \\
\hline BMI $\left(\mathrm{kg} / \mathrm{m}^{2}\right)$ & $26.6 \pm 2.6$ & $25.2 \pm 2.3$ \\
\hline Glucose $(\mathrm{mmol} / \mathrm{L})$ & $8.3 \pm 2.4$ & $8.7 \pm 2.8$ \\
\hline $\begin{array}{l}\text { Glycosylated hemoglobin } \\
\text { (\%) }\end{array}$ & $7.8 \pm 1.2$ & $8.2 \pm 1.7$ \\
\hline Insulin $(\mu \mathrm{IU} / \mathrm{mL})$ & $1.8 \pm 0.3$ & $1.1 \pm 0.3$ \\
\hline FRAP (mmol/L) & $0.7 \pm 0.2$ & $0.7 \pm 0.2$ \\
\hline $\mathrm{SOD}(\mathrm{U} / \mathrm{mL})$ & $107.0 \pm 25.8$ & $111.7 \pm 16.0$ \\
\hline GSH-Px $(\mathrm{U} / \mathrm{L})$ & $172.8 \pm 96.6$ & $161.9 \pm 91.0$ \\
\hline $\mathrm{LDH}(\mathrm{U} / \mathrm{L})$ & $233.5 \pm 59.8$ & $253.8 \pm 110.8$ \\
\hline GSH $(\mathrm{g} / \mathrm{L})$ & $19.4 \pm 6.8$ & $20.3 \pm 8.0$ \\
\hline $\operatorname{MDA}(\mathrm{nmol} / \mathrm{mL})$ & $16.9 \pm 8.2$ & $18.7 \pm 6.0$ \\
\hline
\end{tabular}

shown in Table 1 , there was no significant difference between the two groups in body weight, BMI, and serum biomedical parameters related to glucose metabolism and antioxidant function. There was also no significant difference between the two groups at baseline in male and female (data were not shown).

\section{Dietary Intakes of Energy and Nutrients}

There was no significant difference in the dietary intake of either energy or nutrients between the two groups (Table 2).

\section{Glucose Metabolism}

There was no significant difference between the glucose metabolism data at baseline and the corresponding data at 18 weeks in the control and Chinese propolis groups (Table 3 ).
Table 2 Daily intakes of energy and nutrients in patients with T2DM

\begin{tabular}{lcc}
\hline Parameter & $\begin{array}{l}\text { Control } \\
(\boldsymbol{n}=\mathbf{3 0})\end{array}$ & $\begin{array}{l}\text { Chinese } \\
\text { propolis } \\
(\boldsymbol{n}=\mathbf{2 5})\end{array}$ \\
\hline Energy (kcal) & $1495.2 \pm 346.5$ & $1445.9 \pm 448.4$ \\
Protein $(\mathrm{g})$ & $59.6 \pm 15.9$ & $56.3 \pm 16.1$ \\
Lipids $(\mathrm{g})$ & $42.8 \pm 17.1$ & $45.8 \pm 25.2$ \\
Cholesterol (mg) & $471.9 \pm 226.4$ & $458.6 \pm 163.8$ \\
Carbohydrates $(\mathrm{g})$ & $223.9 \pm 52.5$ & $207.9 \pm 58.3$ \\
Fiber $(\mathrm{g})$ & $12.4 \pm 4.7$ & $12.5 \pm 4.1$ \\
Retinol $(\mu \mathrm{g} \mathrm{RE})$ & $470.5 \pm 223.4$ & $498.2 \pm 313.4$ \\
Thiamin $(\mathrm{mg})$ & $0.8 \pm 0.3$ & $0.8 \pm 0.4$ \\
Riboflavin $(\mathrm{mg})$ & $0.8 \pm 0.3$ & $0.9 \pm 0.4$ \\
Niacin $(\mathrm{mg})$ & $11.0 \pm 3.9$ & $11.1 \pm 4.3$ \\
Ascorbic acid $(\mathrm{mg})$ & $94.1 \pm 38.9$ & $100.1 \pm 66.0$ \\
Tocopherol $(\mathrm{mg})$ & $13.2 \pm 8.5$ & $15.6 \pm 6.3$ \\
Potassium $(\mathrm{mg})$ & $1809.4 \pm 540.4$ & $1769.8 \pm 558.1$ \\
Sodium $(\mathrm{mg})$ & $831.9 \pm 408.0$ & $808.8 \pm 375.9$ \\
Calcium $(\mathrm{mg})$ & $512.8 \pm 195.2$ & $521.1 \pm 350.1$ \\
Iron $(\mathrm{mg})$ & $19.6 \pm 9.9$ & $19.2 \pm 9.3$ \\
Zinc $(\mathrm{mg})$ & $8.6 \pm 2.3$ & $8.2 \pm 2.5$ \\
Selenium $(\mu \mathrm{g})$ & $48.3 \pm 16.6$ & $46.1 \pm 15.3$ \\
\hline & &
\end{tabular}

\section{Antioxidant Function and Inflammatory Cytokines}

After consuming Chinese propolis, serum GSH, flavonoids, and polyphenols were all significantly increased compared with the control group: by $236.4 \% \quad(p=0.000), \quad 24.5 \%$ $(p=0.004)$, and $6.3 \%(p=0.019)$, respectively. Interestingly, serum LDH was significantly decreased $(p=0.004)$, and IL-6 was increased $(p=0.004)$ in the Chinese propolis group compared to the control group. However, no significant difference in serum FRAP, SOD, GSHPx, MDA, carbonyls, IL- $1 \beta$, and TNF- $\alpha$ was observed between the two groups (Table 4). 
Table 3 Comparison of the glucose metabolism data between baseline and the end of the trial in T2DM patients

\begin{tabular}{llllll}
\hline Parameter & Control & & & \multicolumn{2}{l}{ Chinese propolis } \\
\cline { 2 - 3 } & Baseline & $\mathbf{1 8 ~ w e e k s}$ & & Baseline & 18 weeks \\
\hline Glucose (mmol/L) & $8.3 \pm 2.4$ & $8.4 \pm 2.4$ & & $8.7 \pm 2.8$ & $8.5 \pm 2.0$ \\
Glycosylated hemoglobin (\%) & $7.8 \pm 1.2$ & $7.6 \pm 1.2$ & & $8.2 \pm 1.7$ & $7.9 \pm 1.4$ \\
Insulin (uIU/mL) & $1.2 \pm 0.3$ & $1.2 \pm 0.3$ & & $1.1 \pm 0.3$ & $1.0 \pm 0.2$ \\
\hline
\end{tabular}

Table 4 Antioxidant function and inflammatory cytokines in T2DM patients at the end of the trial

\begin{tabular}{lcc}
\hline Parameter & $\begin{array}{l}\text { Control } \\
(\boldsymbol{n}=\mathbf{3 0})\end{array}$ & $\begin{array}{l}\text { Chinese propolis } \\
(\boldsymbol{n}=\mathbf{2 5})\end{array}$ \\
\hline FRAP $(\mathrm{mmol} / \mathrm{L})$ & $0.7 \pm 0.1$ & $0.7 \pm 0.3$ \\
GSH $(\mathrm{g} / \mathrm{L})$ & $2.2 \pm 1.0$ & $7.4 \pm 1.4^{*}$ \\
$\begin{array}{l}\text { Total flavonoids } \\
\quad(\mathrm{mg} / \mathrm{L})\end{array}$ & $51.5 \pm 13.1$ & $64.1 \pm 15.4^{*}$ \\
Total polyphenols & $199.9 \pm 12.6$ & $212.4 \pm 24.2^{*}$ \\
$\quad(\mathrm{mg} / \mathrm{L})$ & & \\
SOD $(\mathrm{U} / \mathrm{mL})$ & $102.8 \pm 3.1$ & $104.3 \pm 3.4$ \\
GSH-Px $(\mathrm{U} / \mathrm{L})$ & $253.7 \pm 74.9$ & $262.2 \pm 56.4$ \\
LDH $(\mathrm{U} / \mathrm{L})$ & $1446.7 \pm 202.1$ & $1224.9 \pm 318.5^{*}$ \\
MDA (mmol/L) & $3.9 \pm 1.2$ & $4.3 \pm 0.9$ \\
Carbonyls $(\mathrm{nmol} /$ & $0.6 \pm 0.1$ & $0.6 \pm 0.1$ \\
$\mathrm{mg}$ prot $)$ & & \\
IL-6 (pg/mL) & $3.1 \pm 0.9$ & $3.7 \pm 1.2^{*}$ \\
IL-1 $\beta(\mathrm{pg} / \mathrm{mL})$ & $18.7 \pm 3.5$ & $18.6 \pm 3.8$ \\
TNF- $\alpha(\mathrm{pg} / \mathrm{mL})$ & $20.7 \pm 3.7$ & $20.6 \pm 4.1$ \\
\hline
\end{tabular}

${ }^{*} p<0.05$ compared with control

Serum GSH was significantly increased at the end of the trial in both males and females in the Chinese propolis group. However, LDH activity was notably decreased in both genders in the Chinese propolis group at the end of the trial. Total polyphenols, total flavonoids, and IL-6 were all increased in both females and males in the Chinese propolis group at the end of the trial, although only the females showed statistically significant increases in these parameters (Table 5).

\section{DISCUSSION}

Diabetes mellitus (DM) is one of the most common metabolic disorders in humans, and is characterized by hyperglycemia due to a shortage of and/or insufficient action of insulin [25]. In type 2 diabetes mellitus (T2DM), the most common type of DM, insulin resistance decreases the response of the peripheral tissues to insulin [26]. Significant increases in reactive oxygen species (ROS) production and oxidative damage have been observed in patients with DM $[27,28]$, accompanied by lower serum levels of GSH, impaired antioxidant enzymatic activities, and higher serum levels of protein carbonyls and MDA [29-32]. Evidence from both experimental and clinical studies suggests that oxidative stress is involved in the development of insulin resistance and $\beta$-cell dysfunction, and plays a major role in the pathogenesis of T2DM [33-36]. Meanwhile, hyperglycemia also contributes to oxidative stress through several pathways: polyol, hexosamine, protein kinase $\mathrm{C}$, glycolysis, and advanced glycation end-product production $[37,38]$. Therefore, it is very important to improve antioxidant function in T2DM in order to protect against oxidative stress.

Several studies have revealed that polyphenols in natural products can help to considerably reduce oxidative stress in animals and patients with T2DM [39-42]. Propolis is one of the richest sources of plant polyphenols, including flavonoids, and presents strong antioxidant activity [43-46]. Previous studies have measured the total polyphenol content in Chinese propolis as $139.12-275.59 \mathrm{mg} / \mathrm{g}$, and the total flavonoid content as 127.58-227.24 mg/g [12, 47]. In the present 
Table 5 Effects of Chinese propolis on each gender by the end of the trial

\begin{tabular}{|c|c|c|c|c|}
\hline \multirow[t]{2}{*}{ Parameter } & \multicolumn{2}{|l|}{ Male } & \multicolumn{2}{|l|}{ Female } \\
\hline & Control & Chinese propolis & Control & Chinese propolis \\
\hline Glucose $(\mathrm{mmol} / \mathrm{L})$ & $8.5 \pm 2.5$ & $8.6 \pm 2.2$ & $8.4 \pm 2.3$ & $9.4 \pm 3.1$ \\
\hline Glycosylated hemoglobin (\%) & $7.6 \pm 0.9$ & $7.8 \pm 1.1$ & $7.8 \pm 1.4$ & $7.9 \pm 1.5$ \\
\hline Insulin $(\mu \mathrm{IU} / \mathrm{mL})$ & $1.2 \pm 0.3$ & $0.9 \pm 0.2$ & $1.2 \pm 0.3$ & $1.1 \pm 0.2$ \\
\hline Adiponectin (mg/L) & $0.7 \pm 0.1$ & $0.7 \pm 0.2$ & $0.7 \pm 0.2$ & $0.7 \pm 0.2$ \\
\hline Aldose reductase $(\mu \mathrm{g} / \mathrm{L})$ & $0.7 \pm 0.4$ & $1.1 \pm 0.5$ & $1.4 \pm 0.6$ & $1.4 \pm 0.4$ \\
\hline Total polyphenols (mg/L) & $204.4 \pm 13.1$ & $208.0 \pm 13.3$ & $196.2 \pm 11.3$ & $214.4 \pm 25.1^{*}$ \\
\hline Total flavonoids (mg/L) & $55.8 \pm 13.4$ & $61.2 \pm 12.1$ & $48.1 \pm 12.2$ & $65.8 \pm 17.1^{*}$ \\
\hline $\mathrm{GSH}(\mathrm{g} / \mathrm{L})$ & $2.0 \pm 0.8$ & $7.2 \pm 1.0^{*}$ & $2.0 \pm 1.5$ & $7.4 \pm 1.6^{*}$ \\
\hline FRAP $(\mathrm{mmol} / \mathrm{L})$ & $0.8 \pm 0.1$ & $0.7 \pm 0.3$ & $0.7 \pm 0.1$ & $0.7 \pm 0.2$ \\
\hline SOD $(U)$ & $101.7 \pm 3.5$ & $103.8 \pm 5.1$ & $103.6 \pm 2.5$ & $104.4 \pm 2.5$ \\
\hline GSH-Px (U) & $281.1 \pm 71.2$ & $267.1 \pm 56.9$ & $231.4 \pm 72.3$ & $259.9 \pm 57.7$ \\
\hline $\mathrm{LDH}(\mathrm{U} / \mathrm{L})$ & $1466.4 \pm 195.5$ & $1242.0 \pm 176.5^{*}$ & $1431.0 \pm 212.6$ & $1292.6 \pm 208.0^{*}$ \\
\hline $\operatorname{MDA}(\mathrm{nmol} / \mathrm{ml})$ & $4.3 \pm 1.3$ & $4.23 \pm 0.64$ & $3.7 \pm 1.1$ & $4.3 \pm 1.0$ \\
\hline Carbonyls (nmol/mg prot) & $0.6 \pm 0.1$ & $0.5 \pm 0.1$ & $0.6 \pm 0.1$ & $0.6 \pm 0.1$ \\
\hline IL-6 (pg/mL) & $3.2 \pm 0.9$ & $3.7 \pm 1.7$ & $2.9 \pm 0.9$ & $3.7 \pm 0.9^{*}$ \\
\hline $\mathrm{IL}-1 \beta(\mathrm{pg} / \mathrm{mL})$ & $19.2 \pm 3.0$ & $18.3 \pm 4.5$ & $18.3 \pm 4.0$ & $18.7 \pm 3.6$ \\
\hline TNF- $\alpha(\mathrm{pg} / \mathrm{mL})$ & $21.3 \pm 3.0$ & $17.9 \pm 4.6$ & $20.1 \pm 4.4$ & $21.5 \pm 3.7$ \\
\hline
\end{tabular}

${ }^{*} p<0.05$, compared with control

study, we demonstrated that consumption of Chinese propolis significantly elevated serum GSH, flavonoid, and polyphenol levels in patients with T2DM after 18 weeks of treatment, indicating that Chinese propolis was effective at increasing the availability of antioxidants. Mujica et al. also found that serum GSH content was significantly increased after propolis treatment in a human population in Chile, which is consistent with our results [48]. In comparison with Brazilian green propolis [49], we found that Chinese propolis increased serum total flavonoids to a greater degree. This appears to be because the total flavonoid content in Chinese propolis is higher than that in Brazilian green propolis (163.65 vs $98.46 \mathrm{mg} / \mathrm{g}$ ) [12]. Interestingly, females seemed to be more sensitive to flavonoid and polyphenol consumption in the present study. This might be related to the gender-dependent hepatic activity of the cytochrome P450 family [50].

It was reported that propolis has a remarkable effect on glucose metabolism in vitro and in vivo. Ueda et al. demonstrated that propolis protects against hyperglycemia by promoting glucose uptake and utility [51]. Other researchers found that propolis modulated glucose metabolism by decreasing glucose levels, increasing plasma insulin levels, improving insulin sensitivity, and reducing serum glycated hemoglobin in rats with diabetes. Besides those effects, propolis also improved antioxidant function by inhibiting lipid peroxidation, enhancing the activities of antioxidant enzymes, and improving antioxidant function in rats with diabetes mellitus [9, 11, 19, 52-55].

Regrettably, we could not confirm the hypoglycemic effects of Chinese propolis in 
T2DM patients in the present study. Similar results were recently reported by Zhao et al. [49] and Fukuda et al. [56], who found that Brazilian green propolis did not significantly improve glucose metabolism. We cannot currently explain this discrepancy between animal models and clinical trials. More studies are needed to validate the possible role of Chinese or Brazilian green propolis in improving glucose metabolism in patients with T2DM.

$\mathrm{LDH}$, an enzyme involved in L-lactate metabolism, is an important marker in the pathophysiology and therapy of T2DM [57]. Under normal conditions, LDH release is limited. However, both cell damage and inflammation are involved in the pathogenesis of chronic diseases such as T2DM, and these are accompanied by enhanced serum LDH activity $[57,58]$. In this study, the notable reduction in serum LDH activity suggests that the administration of Chinese propolis protects against cellular injury and inflammation in patients with T2DM, possibly by increasing the availability of antioxidants such as GSH, flavonoids, and polyphenols.

IL-6 is considered a proinflammatory cytokine [59]. It was reported that T2DM patients show higher levels of inflammatory cytokines such as IL-6, which may contribute to the chronic inflammation associated with T2DM [60]. However, studies have found that IL-6 suppresses inflammation response in several animal models $[61,62]$, and that it plays a crucial role in controlling the levels of proinflammatory cytokines $[63,64]$. Therefore, Scheller et al. stated that IL-6 has both anti- and proinflammatory properties [65]. In this study, we found that serum IL-6 was significantly increased after Chinese propolis treatment, which may be due to the stimulatory action of propolis towards the secretion of IL-6. We believe that increasing IL-6 helps to improve the chronic low-grade inflammation associated with T2DM.

However, there were several limitations of this study. A placebo was not administered to the control group, and only a high dose of Chinese propolis was given to the treatment group. The trial was also not a double-blind trial. Moreover, the effective components in Chinese propolis have not been identified. In addition, a human trial indicated that the longterm use of the artificial antioxidant $R R R$ - $\alpha$-tocopheryl acetate may be harmful to patients with diabetes [66]. Propolis is rich in natural antioxidants such as polyphenols. Considering the biochemical effects of artificial antioxidants and natural antioxidants, further studies should be done to discern any possible harmful effects of Chinese propolis consumption.

\section{CONCLUSION}

In summary, this study demonstrates that Chinese propolis is effective at increasing serum antioxidant parameters such as GSH, flavonoid, and polyphenol levels in T2DM patients.

\section{ACKNOWLEDGEMENTS}

Authorship. All named authors meet the International Committee of Medical Journal Editors (ICMJE) criteria for authorship for this manuscript, take responsibility for the integrity of the work as a whole, and have given final approval of the version to be published.

Funding. This study and the article processing charges were funded by a grant from the Nutrition and Science Foundation of By-Health Co., Ltd. (no. TY0111102).

Disclosures. Weina Gao, Lingling Pu, Jingyu Wei, Zhanxin Yao, Yawen Wang, Tala Shi, Liting Zhao, Changya Jiao, and Changjiang Guo have nothing to disclose.

Compliance with Ethics Guidelines. The protocol was approved by the Ethics Committee of Tianjin Institute of Health and Environmental Medicine (TIHE-TY-20130428). All procedures followed were in accordance with the ethical standards of the responsible committee on human experimentation (institutional and national) and with the Helsinki Declaration of 1964, as revised in 2013. Informed consent was obtained from all patients before they were included in the study. 
Data Availability. The datasets obtained and/or analyzed during the current study are available from the corresponding author on reasonable request.

Open Access. This article is distributed under the terms of the Creative Commons Attribution-NonCommercial 4.0 International License (http://creativecommons.org/licenses/ by-nc/4.0/), which permits any noncommercial use, distribution, and reproduction in any medium, provided you give appropriate credit to the original author(s) and the source, provide a link to the Creative Commons license, and indicate if changes were made.

Author Contribution Weina Gao and Lingling $\mathrm{Pu}$ conceived and designed the experiments. Weina Gao, Lingling Pu, Jingyu Wei, Zhanxin Yao, Yawen Wang, Tala Shi, and Liting Zhao performed the experiments. Weina Gao, Liting Zhao, and Changya Jiao analyzed the data. Weina Gao, Lingling $\mathrm{Pu}$, and Changjiang Guo prepared the manuscript.

\section{REFERENCES}

1. Huang S, Zhang CP, Wang K, Li GQ, Hu FL. Recent advances in the chemical composition of propolis. Molecules. 2014;19(12):19610-32.

2. Aoi W, Hosogi S, Niisato N, Yokoyama N, Hayata H, Miyazaki H, Kusuzaki K, Fukuda T, Fukui M, Nakamura N, Marunaka Y. Improvement of insulin resistance, blood pressure and interstitial $\mathrm{pH}$ in early developmental stage of insulin resistance in OLETF rats by intake of propolis extracts. Biochem Biophys Res Commun. 2013;432(4):650-3.

3. Sun LP, Xu X, Hwang HH, Wang X, Su KY, Chen YL. Dichloromethane extracts of propolis protect cell from oxygen-glucose deprivation-induced oxidative stress via reducing apoptosis. Food Nutr Res. 2016;60:30081.

4. Dantas Silva RP, Machado BA, Barreto GA, Costa SS, Andrade LN, Amaral RG, Carvalho AA, Padilha FF, Barbosa JD, Umsza-Guez MA. Antioxidant, antimicrobial, antiparasitic, and cytotoxic properties of various Brazilian propolis extracts. PLoS One. 2017;12(3):e0172585.

5. Sulaiman GM, Al Sammarrae KW, Ad'hiah AH, Zucchetti M, Frapolli R, Bello E, Erba E, D’Incalci M,
Bagnati R. Chemical characterization of Iraqi propolis samples and assessing their antioxidant potentials. Food Chem Toxicol. 2011;49(9):2415-21.

6. Righi AA, Alves TR, Negri G, Marques LM, Breyer H, Salatino A. Brazilian red propolis: unreported substances, antioxidant and antimicrobial activities. J Sci Food Agric. 2011;91(13):2363-70.

7. Dos Santos Thomazelli AP, Tomiotto-Pellissier F, da Silva SS, Panis C, Orsini TM, Cataneo AH, MirandaSapla MM, Custódio LA, Tatakihara VL, Bordignon J, Silveira GF, Sforcin JM, Pavanelli WR, ConchonCosta I. Brazilian propolis promotes immunomodulation on human cells from American Tegumentar Leishmaniasis patients and healthy donors infected with L braziliensis. Cell Immunol. 2017;311:22-7.

8. Szliszka E, Kucharska AZ, Sokół-Łętowska A, Mertas A, Czuba ZP, Król W. Chemical composition and anti-inflammatory effect of ethanolic extract of Brazilian green propolis on activated J774A.1 macrophages. Evid Based Complement Altern Med. 2013;2013:976415.

9. El-Sayed ESM, Abo-Salem OM, Aly HA, Mansour AM. Potential antidiabetic and hypolipidemic effects of propolis extract in streptozotocin-induced diabetic rats. Pak J Pharm Sci. 2009;22(2):168-74.

10. Abo-Salem OM, El-Edel RH, Harisa GE, El-Halawany $\mathrm{N}$, Ghonaim MM. Experimental diabetic nephropathy can be prevented by propolis: effect on metabolic disturbances and renal oxidative parameters. Pak J Pharm Sci. 2009;22(2):205-10.

11. Zhang NN, Wu JQ, Gao WN, Wei JY, Pu LL, Jiao CY, Guo CJ, Chang $H$. The comparative study of oxidative stress in rats with diabetes mellitus by propolis from different origins. Chin J Food Hyg. 2014;26(1):23-6 (In Chinese).

12. Wu J, Gao W, Wei J, Pu L, Jiao C, Guo C. Comparative study on the effective components in propolis from different areas. Food Nutr China. 2013;19(7):62-5 (In Chinese).

13. American Diabetes Association. Standards of medical care in diabetes-2010. Diabetes Care. 2010;33(1):S11-61.

14. World Health Organization. International guide for monitoring alcohol consumption and related harm. Geneva: Department of Mental Health and Substance Dependence, Noncommunicable Diseases and Mental Health Cluster, World Health Organization; 2000.

15. Husten CG. How should we define light or intermittent smoking? Does it matter? Nicotine Tob Res. 2009;11(2):111-21. 
16. Dolgin M, Fox AC, Gorlin R, Levin RI, Association $\mathrm{NYH}$, New York Heart Association, Criteria Committee. Nomenclature and criteria for diagnosis of diseases of the heart and great vessels. 9th ed. Lippincott Williams and Wilkins: Boston; 1994.

17. KDIGO Board Members. KDIGO 2012 clinical practice guideline for the evaluation and management of chronic kidney disease, chapter 1: definition and classification of CKD. Kidney Int. 2013;3(1):19-62.

18. Postuma RB, Berg D, Stern M, Poewe W, Olanow CW, Oertel W, Obeso J, Marek K, Litvan I, Lang AE, Halliday G, Goetz CG, Gasser T, Dubois B, Chan P, Bloem BR, Adler CH, Deuschl G. MDS clinical diagnostic criteria for Parkinson's disease. Mov Disord. 2015;30(12):1591-601.

19. Li Y, Chen M, Xuan H, Hu F. Effects of encapsulated propolis on blood glycemic control, lipid metabolism, and insulin resistance in type 2 diabetes mellitus rats. Evid Based Complement Altern Med 2012;981896

20. Institute of Nutrition and Food Safety, China Center for Disease Control and Prevention. China food composition 2009. Beijing: Peking University Medical; 2009.

21. Benzie IF, Strain JJ. The ferric reducing ability of plasma (FRAP) as a measure of "antioxidant power": the FRAP assay. Anal Biochem. 1996;239(1):70-6.

22. Ohkawa H, Ohishi N, Yagi K. Assay for lipid peroxides in animal tissues by thiobarbituric acid reaction. Anal Biochem. 1979;95(2):351-8.

23. Jia Z, Tang M, Wu J. The determination of flavonoid contents in mulberry and their scavenging effect on superoxide radicals. Food Chem. 1999;64(4):555-9.

24. Ainsworth EAI, Gillespie KM. Estimation of total phenolic content and other oxidation substrates in plant tissues using Folin-Ciocalteu reagent. Nat Protoc. 2007;2(4):875-7.

25. Expert Committee on the Diagnosis and Classification of Diabetes Mellitus. Report of the Expert Committee on the Diagnosis and Classification of Diabetes Mellitus. Diabetes Care. 2003;26(Suppl 1):S5-20.

26. International Diabetes Federation. IDF diabetes atlas. 6th ed. Brussels: International Diabetes Federation; 2014. http://www.idf.org/diabetesatlas (accessed 3 May 2017).

27. Karunakaran U, Park KG. A systematic review of oxidative stress and safety of antioxidants in diabetes: focus on islets and their defense. Diabetes Metab J. 2013;37(2):106-12.
28. Aouacheri O, Saka S, Krim M, Messaadia A, Maidi I. The investigation of the oxidative stress-related parameters in type 2 diabetes mellitus. Can J Diabetes. 2015;39(1):44-9.

29. Al-Maskari MY, Waly MI, Ali A, Al-Shuaibi YS, Ouhtit A. Folate and vitamin B12 deficiency and hyperhomocysteinemia promote oxidative stress in adult type 2 diabetes. Nutrition. 2012;28(7-8):e23-6.

30. Casoinic F, Sampelean D, Buzoianu AD, Hancu N, Baston D. Serum levels of oxidative stress markers in patients with type 2 diabetes mellitus and nonalcoholic steatohepatitis. Rom J Intern Med. 2016;54(4):228-36.

31. Rani AJ, Mythili SV. Study on total antioxidant status in relation to oxidative stress in type 2 diabetes mellitus. J Clin Diagn Res. 2014;8(3):108-10.

32. Bandeira Sde M, Guedes Gda S, da Fonseca LJ, Pires AS, Gelain DP, Moreira JC, Rabelo LA, Vasconcelos SM, Goulart MO. Characterization of blood oxidative stress in type 2 diabetes mellitus patients: increase in lipid peroxidation and SOD activity. Oxid Med Cell Longev. 2012;2012:819310.

33. Alam MM, Iqbal S, Naseem I. Ameliorative effect of riboflavin on hyperglycemia, oxidative stress and DNA damage in type-2 diabetic mice: mechanistic and therapeutic strategies. Arch Biochem Biophys. 2015;584:10-9.

34. Tiganis T. Reactive oxygen species and insulin resistance: the good, the bad and the ugly. Trends Pharmacol Sci. 2011;32(2):82-9.

35. Soskić SS, Dobutović BD, Sudar EM, Obradović MM, Nikolić DM, Djordjevic JD, Radak DJ, Mikhailidis $\mathrm{DP}$, Isenović ER. Regulation of inducible nitric oxide synthase (iNOS) and its potential role in insulin resistance, diabetes and heart failure. Open Cardiovasc Med J. 2011;5:153-63.

36. Pitocco D, Tesauro M, Alessandro R, Ghirlanda G, Cardillo C. Oxidative stress in diabetes: implications for vascular and other complications. Int J Mol Sci. 2013;14(11):21525-50.

37. Román-Pintos LM, Villegas-Rivera G, RodríguezCarrizalez AD, Miranda-Díaz AG, Cardona-Muñoz EG. Diabetic polyneuropathy in type 2 diabetes mellitus: inflammation, oxidative stress, and mitochondrial function. J Diabetes Res. 2016;2016:3425617.

38. Patche J, Girard D, Catan A, Boyer F, Dobi A, Planesse C, Diotel N, Guerin-Dubourg A, Baret P, Bravo SB, Paradela-Dobarro B, Álvarez E, Essop MF, Meilhac O, Bourdon E, Rondeau P. Diabetes-induced hepatic oxidative stress: a new pathogenic role for 
glycated albumin. Free Radic Biol Med. 2017;102:133-48.

39. Dragan S, Andrica F, Serban MC, Timar R. Polyphenols-rich natural products for treatment of diabetes. Curr Med Chem. 2015;22(1):14-22.

40. Palma-Duran SA, Vlassopoulos A, Lean M, Govan L, Combet E. Nutritional intervention and impact of polyphenol on glycohemoglobin (HbA1c) in nondiabetic and type 2 diabetic subjects: systematic review and meta-analysis. Crit Rev Food Sci Nutr. 2017;57(5):975-86.

41. Lin D, Xiao M, Zhao J, Li Z, Xing B, Li X, Kong M, Li L, Zhang Q, Liu Y, Chen H, Qin W, Wu H, Chen S. An overview of plant phenolic compounds and their importance in human nutrition and management of type 2 diabetes. Molecules. 2016;21(10):E1374.

42. Amin MM, Arbid MS. Estimation of ellagic acid and/or repaglinide effects on insulin signaling, oxidative stress, and inflammatory mediators of liver, pancreas, adipose tissue, and brain in insulin resistant/type 2 diabetic rats. Appl Physiol Nutr Metab. 2017;42(2):181-92.

43. Szliszka E, Krol W. Polyphenols isolated from propolis augment TRAIL-induced apoptosis in cancer cells. Evid Based Complement Altern Med. 2013;2013:731940.

44. Falcão SII, Vale N, Gomes P, Domingues MR, Freire C, Cardoso SM, Vilas-Boas M. Phenolic profiling of Portuguese propolis by LC-MS spectrometry: uncommon propolis rich in flavonoid glycosides. Phytochem Anal. 2013;24(4):309-18.

45. Nina N, Quispe C, Jiménez-Aspee F, Theoduloz C, Feresín GE, Lima B, Leiva E, Schmeda-Hirschmann G. Antibacterial activity, antioxidant effect and chemical composition of propolis from the Región del Maule, Central Chile. Molecules. 2015;20(10):18144-67.

46. Salas AL, Alberto MR, Zampini IC, Cuello AS, Maldonado L, Ríos JL, Schmeda-Hirschmann G, Isla MI. Biological activities of polyphenols-enriched propolis from Argentina arid regions. Phytomedicine. 2016;23(1):27-31.

47. Wang K, Ping S, Huang S, Hu L, Xuan H, Zhang C, $\mathrm{Hu}$ F. Molecular mechanisms underlying the in vitro anti-inflammatory effects of a flavonoidrich ethanol extract from Chinese propolis (poplar type). Evid Based Complement Altern Med. 2013;2013:127672.

48. Mujica V, Orrego R, Pérez J, Romero P, Ovalle P, Zúñiga-Hernández J, Arredondo $\mathrm{M}$, Leiva E. The role of propolis in oxidative stress and lipid metabolism: a randomized controlled trial. Evid Based Complement Altern Med. 2017;2017:4272940.

49. Zhao L, Pu L, Wei J, Li J, Wu J, Xin Z, Gao W, Guo C. Brazilian green propolis improves antioxidant function in patients with type 2 diabetes mellitus. Int J Environ Res Public Health. 2016;13(5):E498.

50. Ekstrand B, Rasmussen MK, Woll F, Zlabek V, Zamaratskaia G. In vitro gender-dependent inhibition of porcine cytochrome p450 activity by selected flavonoids and phenolic acids. Biomed Res Int. 2015;2015:387918.

51. Ueda M, Hayashibara K, Ashida H. Propolis extract promotes translocation of glucose transporter 4 and glucose uptake through both PI3K- and AMPK-dependent pathways in skeletal muscle. BioFactors. 2013;39(4):457-66.

52. Al-Hariri M, Eldin TG, Abu-Hozaifa B, Elnour A. Glycemic control and anti-osteopathic effect of propolis in diabetic rats. Diabetes Metab Syndr Obes. 2011;4:377-84.

53. El Rabey HA, Al-Seeni MN, Bakhashwain AS. The antidiabetic activity of Nigella sativa and propolis on streptozotocin-induced diabetes and diabetic nephropathy in male rats. Evid Based Complement Altern Med. 2017;2017:5439645.

54. Zhu W, Li YH, Chen ML, Hu FL. Protective effects of Chinese and Brazilian propolis treatment against hepatorenal lesion in diabetic rats. Hum Exp Toxicol. 2011;30(9):1246-55.

55. Fuliang HU, Hepburn HR, Xuan H, Chen M, Daya S, Radloff SE. Effects of propolis on blood glucose, blood lipid and free radicals in rats with diabetes mellitus. Pharmacol Res. 2005;51(2):147-52.

56. Fukuda T, Fukui $M$, Tanaka $M$, Senmaru $T$, Iwase $H$, Yamazaki M, Aoi W, Inui T, Nakamura N, Marunaka Y. Effect of Brazilian green propolis in patients with type 2 diabetes: a double-blind randomized placebo-controlled study. Biomed Rep. 2015;3(3):355-60.

57. Adeva M, González-Lucán M, Seco M, Donapetry C. Enzymes involved in L-lactate metabolism in humans. Mitochondrion. 2013;13(6):615-29.

58. Drent M, Cobben NA, Henderson RF, Wouters EF, van Dieijen-Visser M. Usefulness of lactate dehydrogenase and its isoenzymes as indicators of lung damage or inflammation. Eur Respir J. 1996;9(8):1736-42.

59. Margetic S. Inflammation and haemostasis. Biochem Med (Zagreb). 2012;22(1):49-62. 
60. Domingueti CP, Dusse LM, Carvalho MD, de Sousa LP, Gomes KB, Fernandes AP. Diabetes mellitus: the linkage between oxidative stress, inflammation, hypercoagulability and vascular complications. J Diabetes Complicat. 2016;30(4):738-45.

61. Barton BE, Jackson JV. Protective role of interleukin 6 in the lipopolysaccharide-galactosamine septic shock model. Infect Immun. 1993;61(4):1496-9.

62. Ulich TR, Yin S, Guo K, Yi ES, Remick D, del Castillo J. Intratracheal injection of endotoxin and cytokines. II. Interleukin-6 and transforming growth factor beta inhibit acute inflammation. Am J Pathol. 1991;138(5):1097-101.

63. Puchner A, Blüml S. IL-6 blockade in chronic inflammatory diseases. Wien Med Wochenschr. 2015;165(1-2):14-22.
64. Xing Z, Gauldie J, Cox G, Baumann H, Jordana M, Lei XF, Achong MK. IL-6 is an antiinflammatory cytokine required for controlling local or systemic acute inflammatory responses. J Clin Investig. 1998;101(2):311-20.

65. Scheller J, Chalaris A, Schmidt-Arras D, Rose-John S. The pro- and anti-inflammatory properties of the cytokine interleukin-6. Biochim Biophys Acta. 2011;1813(5):878-88.

66. Lonn E, Bosch J, Yusuf S, Sheridan P, Pogue J, Arnold JM, Ross C, Arnold A, Sleight P, Probstfield J, Dagenais GR; HOPE and HOPE-TOO Trial Investigators. Effects of long-term vitamin E supplementation on cardiovascular events and cancer: a randomized controlled trial. JAMA. 2005;293(11):1338-47. 